\title{
Accelerating growth of HFC-227ea $(1,1,1,2,3,3,3$-heptafluoropropane) in the atmosphere
}

\author{
J. C. Laube $^{1}$, P. Martinerie ${ }^{2}$, E. Witrant ${ }^{3}$, T. Blunier ${ }^{4}$, J. Schwander ${ }^{5}$, C. A. M. Brenninkmeijer ${ }^{6}$, T. J. Schuck ${ }^{6}$, \\ M. Bolder ${ }^{7}$, T. Röckmann ${ }^{7}$, C. van der Veen ${ }^{7}$, H. Bönisch ${ }^{8}$, A. Engel ${ }^{8}$, G. P. Mills ${ }^{1}$, M. J. Newland ${ }^{1}$, D. E. Oram ${ }^{1}$, \\ C. E. Reeves ${ }^{1}$, and W. T. Sturges ${ }^{1}$ \\ ${ }^{1}$ School of Environmental Sciences, University of East Anglia, Norwich, UK \\ ${ }^{2}$ Laboratoire de Glaciologie et Géophysique de l'Environnement (LGGE), CNRS, \\ Université Joseph Fourier-Grenoble, Grenoble, France \\ ${ }^{3}$ Grenoble Image Parole Signal Automatique (GIPSA-lab), Université Joseph Fourier/CNRS, Grenoble, France \\ ${ }^{4}$ Centre for Ice and Climate, University of Copenhagen, Copenhagen, Denmark \\ ${ }^{5}$ Physics Institute, University of Berne, Bern, Switzerland \\ ${ }^{6}$ Max Planck Institute for Chemistry, Air Chemistry Division, Mainz, Germany \\ ${ }^{7}$ Institute for Marine and Atmospheric Research, Utrecht University, Utrecht, The Netherlands \\ ${ }^{8}$ Institute for Atmosphere and Environment, University of Frankfurt, Frankfurt, Germany
}

Received: 16 March 2010 - Published in Atmos. Chem. Phys. Discuss.: 24 March 2010

Revised: 16 June 2010 - Accepted: 30 June 2010 - Published: 2 July 2010

\begin{abstract}
We report the first measurements of 1,1,1,2,3,3,3heptafluoropropane (HFC-227ea), a substitute for ozone depleting compounds, in air samples originating from remote regions of the atmosphere and present evidence for its accelerating growth. Observed mixing ratios ranged from below $0.01 \mathrm{ppt}$ in deep firn air to $0.59 \mathrm{ppt}$ in the current northern mid-latitudinal upper troposphere. Firn air samples collected in Greenland were used to reconstruct a history of atmospheric abundance. Year-on-year increases were deduced, with acceleration in the growth rate from $0.029 \mathrm{ppt}$ per year in 2000 to $0.056 \mathrm{ppt}$ per year in 2007. Upper tropospheric air samples provide evidence for a continuing growth until late 2009. Furthermore we calculated a stratospheric lifetime of 370 years from measurements of air samples collected on board high altitude aircraft and balloons. Emission estimates were determined from the reconstructed atmospheric trend and suggest that current "bottom-up" estimates of global emissions for 2005 are too high by a factor of three.
\end{abstract}

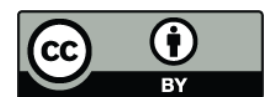

Correspondence to: J. C. Laube (j.laube@uea.ac.uk)

\section{Introduction}

Hydrofluorocarbons (HFCs) are second-generation replacements for compounds responsible for the anthropogenic stratospheric ozone depletion. As they do not contain any chlorine, bromine or iodine their Ozone Depletion Potentials are virtually zero. Due to the phase-out of chlorofluorocarbons (CFCs) and also their first-generation replacements (i.e. hydrochlorofluorocarbons, HCFCs, e.g. Clerbaux and Cunnold (2007)) HFCs have become increasingly important. In return atmospheric growth has been reported in the recent past for many HFCs (e.g. Montzka et al., 1996; Oram et al., 1998; Vollmer et al., 2006; Greally et al., 2007; Stemmler et al., 2007; O'Doherty et al., 2009). HFC-227ea (i.e. $\mathrm{CF}_{3} \mathrm{CHFCF}_{3}$ or $1,1,1,2,3,3,3$-heptafluoropropane) has been proposed for various applications such as a propellant in pharmaceutical or foam-forming aerosols (Deger, 1992; Yquel, 1995; Jager et al., 2005), as a refrigerant (Emmen et al., 2000; Park et al., 2001), in fire extinguishers (Hynes et al., 1998) and also for plasma-etching (Karecki et al., 1998). Jager et al. (2005) even state, that CFCs are already being replaced by approximately 90\% HFC-134a and 10\% HFC227ea in metered dose inhalers (MDIs).

Published by Copernicus Publications on behalf of the European Geosciences Union. 
Additional desirable properties of CFC replacements are relatively low atmospheric lifetimes and low Global Warming Potentials (GWPs). Here, HFC-227ea shows some disadvantages as both its estimated lifetime as well as its reported GWP are relatively high (34.2 years and 3220 on a 100 -year time horizon, Forster et al., 2007) and comparable to those of CFC-11. Despite these perhaps not optimal properties HFC-227ea is being used, and emissions (EDGAR, 2009) reported. Missing so far has been the actual detection of HFC$227 \mathrm{ea}$ in the remote atmosphere, a determination of its rate of growth and "top-down" emission estimates.

\section{Experimental methods}

Air samples were collected from a range of platforms and at various locations:

1. On board a Lufthansa aircraft at cruising altitudes of 8 to $13 \mathrm{~km}$ between Frankfurt (Main), Germany and Cape Town, South Africa on 27 and 28 October 2009 (www. caribic-atmospheric.com).

2. In the mid- and high-latitudinal upper troposphere and stratosphere (10 to $20 \mathrm{~km}$ ) on board the Geophysica high altitude aircraft during two flights from and returning to Oberpfaffenhofen, Germany on 30 October and 4 November $2009\left(48-54^{\circ} \mathrm{N}, 7-12^{\circ} \mathrm{E}\right)$ and one flight from and returning to Kiruna, Sweden on 22 January $2010\left(68-77^{\circ} \mathrm{N}, 20-24^{\circ} \mathrm{E}\right)$.

3. In the tropical upper troposphere and stratosphere with a balloon-borne whole-air-sampler launched in June 2008 near Teresina, Brazil $\left(5^{\circ} 04^{\prime} \mathrm{S}, 42^{\circ} 52^{\prime} \mathrm{W}\right)$ by the French Space Agency CNES (Centre National d'Etudes Spatiales).

4. From deep firn air in Greenland at $77.445^{\circ} \mathrm{N}$, $51.066^{\circ} \mathrm{W}$ and $2484 \mathrm{~m}$ a.s.l. in July 2008 (the North Greenland Eemian Ice Drilling project; NEEM). Four of the 17 measured samples were contaminated with HFC227ea which is attributed to a different type of close-off valve used on those particular sample canisters. These samples were excluded from further analysis.

Please refer to Brenninkmeijer et al. (2007), Kaiser et al. (2006), Laube et al. (2008) as well as to http://neem.nbi. ku.dk/ for further details on sample collection.

All samples were analysed using gas chromatography with mass spectrometric detection (GC-MS). After drying using an on-line drying tube with $\mathrm{Mg}\left(\mathrm{ClO}_{4}\right)_{2}$, condensable trace gases were pre-concentrated from about $300 \mathrm{ml}$ of air at $-78^{\circ} \mathrm{C}$ in a $1 / 16^{\prime \prime}$ sample loop filled with an adsorbent (Hayesep D, 80/100 mesh) which was heated to $100^{\circ} \mathrm{C} \mathrm{im-}$ mediately after injection. Separation was carried out with an Agilent 6890 gas chromatograph using an Agilent GSGasPro column (length $30 \mathrm{~m}$, ID $0.32 \mathrm{~mm}$ ) coupled to a high sensitivity tri-sector (EBE) mass spectrometer (Micromass/Waters AutoSpec). This instrument has a proven detection limit $<1$ attomole and was operated in EI-SIR (Electron Impact-Selected Ion Recording) mode using a mass resolution of 1000. The $\mathrm{GC}$ column temperature was ramped from $-10^{\circ} \mathrm{C}$ to $200^{\circ} \mathrm{C}$ at $10^{\circ} \mathrm{C}$ per minute. $\mathrm{CF}_{3} \mathrm{CHFCF}_{3}$ eluted after about $13.6 \mathrm{~min}$ and was measured by means of the fragment ions $\mathrm{C}_{3} \mathrm{HF}_{6}^{+}\left(\mathrm{m} / z\right.$ 151.00) and $\mathrm{C}_{2} \mathrm{HF}_{4}^{+}(\mathrm{m} / \mathrm{z}$ 101.00). No chromatographic interferences were found for these ions at the given retention time window. In addition, due to the relatively high mass resolution (as compared to common single quadrupole mass spectrometers) a possible interference from an unknown co-eluent is very unlikely.

In order to confirm the identity of the compound and to assign mixing ratios to the air samples we prepared static dilutions of $\mathrm{CF}_{3} \mathrm{CHFCF}_{3}$ in Oxygen-free Nitrogen (OFN) obtained from BOC Gases, UK. For this purpose we constructed a dedicated drum dilution system based on an existing system described in Fraser et al. (1999). To evaluate this system $\mathrm{CF}_{2} \mathrm{Cl}_{2}$ was added as an internal reference and diluted similarly. The resulting mixing ratios (which are dry air mole fractions) agreed with the internationally recognized calibration scale of NOAA (2001 scale) within 1.3\%. Summing up all uncertainties that could affect the calibration values gives about $14 \%$. However, taking into account the good agreement with the NOAA scale for $\mathrm{CF}_{2} \mathrm{Cl}_{2}$ as well as the small variability between calibrations for HFC-227ea $(<4 \%)$ we estimate our scale uncertainty to be not larger than $5 \%$. The air standard used to assign mixing ratios to the samples was found to contain $0.354 \mathrm{ppt} \mathrm{HFC-227ea} \mathrm{and} \mathrm{the} \mathrm{respective}$ average $1 \sigma$ measurement precision was $1.4 \%$. More details on configuration and evaluation of the calibration system can be found in the supplemental information.

To ascertain the potential presence of contaminants, one of the dilutions was measured while running the MS in scan mode across the range $m / z 47$ to 200 . The chromatogram confirmed the purity of both compounds as no significant amounts of other halocarbons were observed. The obtained spectrum can be found in Table 1 and was compared to the one reported by Reizian-Fouley et al. (1997). All major peaks were present except one at $\mathrm{m} / \mathrm{z} 117$ which we did not observe. However, no ion is assigned to this peak in ReizianFouley et al. (1997) and there is no possible primary fragment of 1,1,1,2,3,3,3-heptafluoropropane with such a mass to charge ratio. Therefore we suggest that its occurrence is very likely to have been an instrumental artefact. The observed relative abundances are of limited comparability due to the different experimental setups. We generally observed much higher relative abundances for ions with lower mass to charge ratios which could be caused by different mass discrimination effects of the mass spectrometers or the use of a nonfluorinated internal reference compound (i.e. n-hexadecane) in our study.

Finally, 1,1,2,2,3,3,3-heptafluoropropane as a potential isomeric impurity is unlikely as the chromatographic system 
Table 1. Mass spectral data for HFC-227ea obtained from a $143 \mathrm{ppt}$ dilution in nitrogen as measured on a GC-MS system in scan mode which gives only low mass resolution (see text for details). The spectrum was background-corrected, but some minor residual peaks resulting from the internal mass axis calibration gas (i.e. nhexadecane) remain. The major peaks are the same as in the mass spectrum reported by Reizian-Fouley et al. (1997) except for an additional peak reported at $\mathrm{m} / \mathrm{z}, 117$ which is a very untypical mass fragment for HFC-227ea and was not observed in this study.

\begin{tabular}{ccl}
\hline $\mathrm{m} / \mathrm{z}$ & $\begin{array}{c}\text { Normalised } \\
\text { abundance }\end{array}$ & $\begin{array}{l}\text { Suggested } \\
\text { fragment }\end{array}$ \\
\hline 69 & 999 & $\mathrm{CF}_{3}^{+}$ \\
51 & 272 & $\mathrm{CHF}_{2}^{+}$ \\
82 & 128 & $\mathrm{C}_{2} \mathrm{HF}_{3}^{+}$ \\
50 & 25 & $\mathrm{CF}_{2}^{+}$ \\
151 & 24 & $\mathrm{C}_{3} \mathrm{HF}_{6}^{+}$ \\
55 & 21 & residual n- $_{16} \mathrm{H}_{34}$ \\
63 & 14 & $\mathrm{C}_{2} \mathrm{HF}_{2}^{+}$ \\
70 & 11 & $13 \mathrm{CF}_{3}^{+}$ \\
54 & 9 & res. n- ${ }_{16} \mathrm{H}_{34}$ \\
56 & 8 & res. n- $\mathrm{C}_{16} \mathrm{H}_{34}$ \\
53 & 8 & res. $\mathrm{n}-\mathrm{C}_{16} \mathrm{H}_{34}$ \\
101 & 6 & $\mathrm{C}_{2} \mathrm{HF}_{4}^{+}$ \\
100 & 6 & $\mathrm{C}_{2} \mathrm{~F}_{4}^{+}$ \\
\hline
\end{tabular}

should be able to separate the compounds (boiling point difference of about $2 \mathrm{~K}$ between isomers). However, as an additional check we calculated the ratio of the two ions measured in SIR mode $(\mathrm{m} / \mathrm{z} 151.00$ and 101.00). It was found to be comparable for all samples and dilutions.

\section{Results and discussion}

\subsection{Firn air measurements and results}

The Greenland firn air samples showed good measurement precisions for HFC-227ea and revealed that mixing ratios were monotonically decreasing with increasing depth (Fig. 1). As the age of the air also increases with depth this indicates a recent growth in the atmosphere. Moreover, the very low mixing ratios are observed around $74 \mathrm{~m}$ indicate a recent onset of emissions and thus an entirely anthropogenic origin of the compound.

The relationship between past atmospheric time trends and concentration profiles in firn can be established using models of trace gas transport in firn (e.g. Schwander et al., 1993; Butler et al., 1999; Sturrock et al., 2002 and references therein). Please note, that all of the trends derived from measurements of air entrapped in firn are dependent on the assumption that the respective compound is chemically (no destruction) and physically (no adsorption or dis-
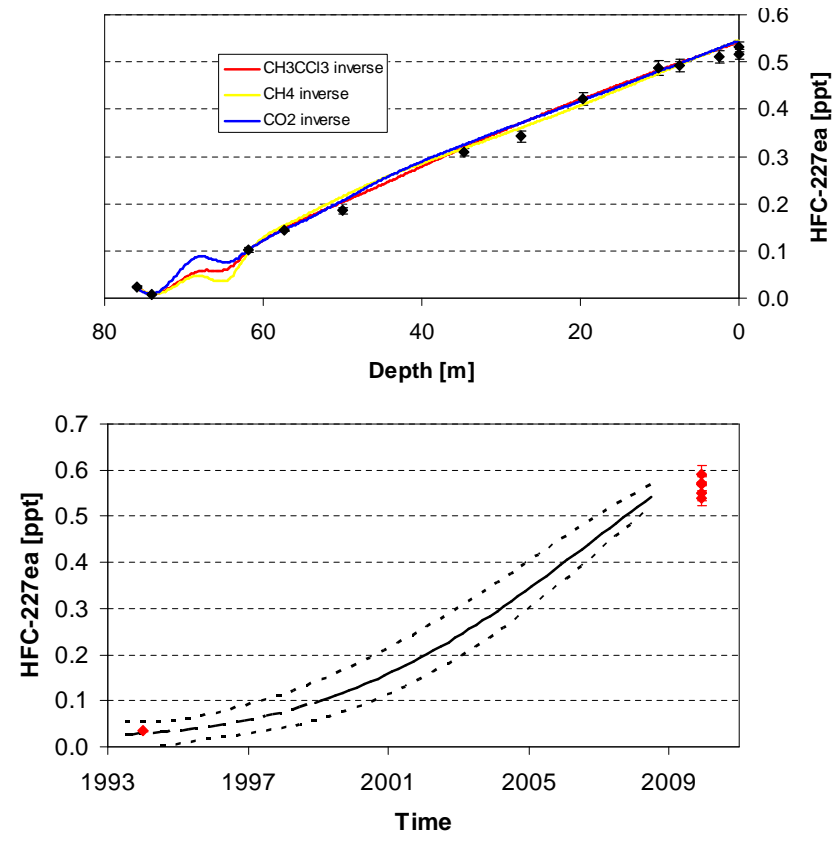

Fig. 1. Mixing ratios of HFC-227ea as a function of depth as measured in air samples collected from deep firn in Greenland in 2008 (upper part) alongside with three modelled diffusivity profiles as described in Sect. 3.1. The lower part shows the northern hemispheric temporal trend inferred from these mixing ratios via inverse modelling. The short-dashed lines represent the maximum of the two $\sigma$ root mean square deviations while the continuous line shows the mean of the three corresponding best estimate trends. The lack of data between 62 and $74 \mathrm{~m}$ leads to high uncertainties in the trend before 1999 which is why it is displayed as a long-dashed line. The additional red points are all from northern mid-latitude samples. They originate from upper tropospheric aircraft samples (2009), and an archived air sample collected at Niwot Ridge near Boulder, USA (1994).

solution) unaffected in the firn over the time periods represented by the measured trends. Here we use direct and inverse models that are developments of those described by Rommelaere et al. (1997), Fabre et al. (2000) and Martinerie et al. (2009). The following is a brief description whereas a fuller description will be given in a forthcoming publication from the NEEM project community. The firn diffusivity is first evaluated using three reference gases: $\mathrm{CO}_{2}$, $\mathrm{CH}_{4}$ and $\mathrm{CH}_{3} \mathrm{CCl}_{3}$, for which measurements were made by NOAA-ESRL, CSIRO Marine and Atmospheric Research, IUP Heidelberg and UEA and atmospheric time trends estimates have been determined. For the latter we used publicly available atmospheric data from NOAA-ESRL (http: //www.esrl.noaa.gov/gmd), AGAGE (http://cdiac.ornl.gov/ ndps/alegage.html, Prinn et al., 2000), the GAW database (WMO Global Atmospheric Watch, World Data Centre for Greenhouse Gases, http://gaw.kishou.go.jp/wdegg/) and firn and ice records from McFarling-Meure et al. (2006) for $\mathrm{CO}_{2}$ and $\mathrm{CH}_{4}$ as well as emission-based atmospheric modelling 
(Martinerie et al., 2009) for $\mathrm{CH}_{3} \mathrm{CCl}_{3}$. For HFC-227ea we further needed to know its diffusion coefficient in air. We used the Chen and Othmer (1962) calculation to derive an estimate for this, not the more commonly used method of Fuller et al. (1966), due to the reportedly greater robustness of the former (Massman, 1998). For HFC-227ea a diffusion coefficient relative to that of $\mathrm{CO}_{2}$ of 0.465 was obtained. A very similar ratio of 0.471 was calculated using the Fuller et al. (1966) parameterisation.

Both a Monte-Carlo approach (Bräunlich et al., 2001) and a linear inverse approach (Rommelaere et al., 1997) were used to infer the atmospheric time trend for the HFC227ea mixing ratios. Consistent results (within the respective model uncertainties) were obtained with the two methods. The time trend obtained with the inverse model (Rommelaere et al., 1997) is shown in Fig. 1 alongside with the actual measurements as a function of depth. It is most likely, that the emissions started in the early 1990s or late 1980s. Please note, that below $0.1 \mathrm{ppt}$ the scenario essentially relies on the last two data points. The data gap in this region of the firn creates high uncertainties and does not allow further constraints on the emission start date or the trend prior to 1999. However, good agreement of the early trend (1993/1994) was observed with a northern hemispheric air sample (Colorado mountains, USA) remotely collected in 1994 (see Fig. 1) although this sample can not be directly compared with the firn air data (different locations). The more recent part of the scenario is better constrained and shows a sustained growth of HFC-227ea since 1999 until mid 2008. The average growth rate accelerated continuously from $0.029 \mathrm{ppt} \mathrm{yr}^{-1}$ in 2000 to $0.053 \mathrm{ppt} \mathrm{yr}^{-1}$ in 2005 and $0.056 \mathrm{ppt} \mathrm{yr}^{-1}$ in 2007. The firn air itself was collected in July 2008, therefore an averaged growth rate cannot be provided for 2008, but mixing ratios continued to increase. Please also note that these growth rates represent only best estimates and contain considerable uncertainties within the envelopes shown in Fig. 1. Additional data from samples collected on board aircraft flying in the Northern Hemispheric upper troposphere in late 2009 clearly indicate a further growth since during this period (see Fig. 1).

\subsection{Emission estimates}

We derived the emissions required to produce the temporal trend in the atmospheric concentrations inferred from the firn air data using a 2-D atmospheric chemistry-transport model. The model contains 24 equal area latitudinal bands and 12 vertical levels, each of $2 \mathrm{~km}$. Thus the latitude band applicable to the NEEM firn site is the most northerly $\left(66.4^{\circ}-\right.$ $90.0^{\circ}$ ) and since the altitude of the site is about $2.5 \mathrm{~km}$, the concentrations for the second level $(2-4 \mathrm{~km})$ were used. The emissions were assigned predominantly to the northern midlatitudes with only $2 \%$ released in the Southern Hemisphere (distribution as in EDGAR, 2009). Using CFC-11, CFC-12 and $\mathrm{CH}_{3} \mathrm{CCl}_{3}$ Reeves et al. (2005) showed that the model's

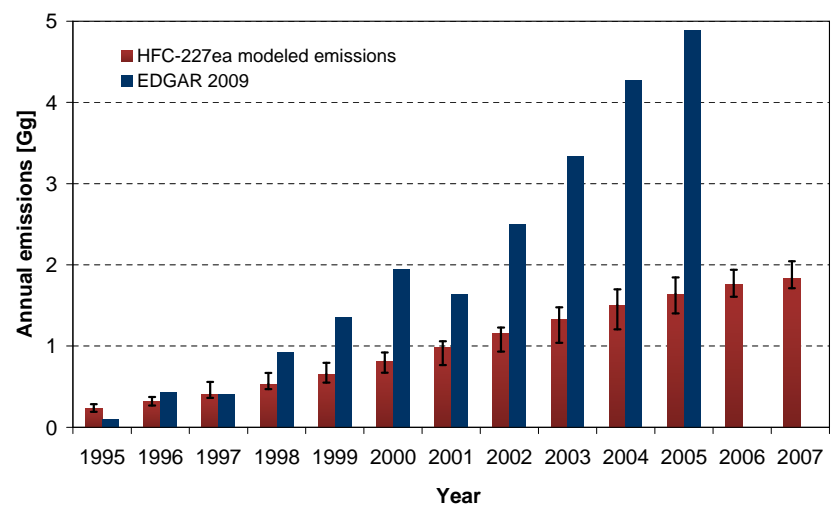

Fig. 2. Emission estimates as derived from trends of HFC-227ea in firn air in comparison with those reported by the EDGAR emission database (EDGAR, 2009). The primary sink for HFC-227ea is reaction with the $\mathrm{OH}$ radical in the troposphere. Therefore error bars were calculated as the root of mean of the squares of the summed uncertainty in the $\mathrm{OH}$ concentration and in the respective reaction rate coefficient as well as firn air related uncertainties (corresponding to the minimum and maximum scenarios in Fig. 1).

transport scheme (Hough, 1989) typically reproduces the observed concentrations in the Arctic to within 10\%, when constrained to observed southern hemispheric concentrations.

The major known atmospheric sink of HFC-227ea is the reaction with the $\mathrm{OH}$ radical (Zellner et al., 1994). The model's $\mathrm{OH}$ field was adjusted to give a partial lifetime for $\mathrm{CH}_{3} \mathrm{CCl}_{3}$, with respect to reaction with $\mathrm{OH}\left(\tau_{\mathrm{OH}}\right)$, in agreement with Clerbaux and Cunnold (2007) (6.1 years) when using a reaction rate coefficient of $\left(1.2 \times 10^{-12}\right)$ $\exp [-1440 / \mathrm{T}] \mathrm{cm}^{3}$ molecule ${ }^{-1} \mathrm{~s}^{-1}$ (Atkinson et al., 2008). The model then gives a value of 46.5 years for $\tau_{\mathrm{OH}}$ for HFC227 ea when using a reaction rate coefficient of $\left(5.3 \times 10^{-13}\right)$ $\exp [-1770 / \mathrm{T}] \mathrm{cm}^{3}$ molecule ${ }^{-1} \mathrm{~s}^{-1}$ (Atkinson et al., 2008). The diffusive transport out of the top of the model is then adjusted to account for stratospheric loss equivalent to a partial lifetime $\left(\tau_{\text {strat }}\right)$ of 450 years which is within the range calculated in Sect. 3.3. Overall the model gives a total lifetime of 42.1 years for HFC-227ea. This is higher than the 34.2 years reported in Clerbaux and Cunnold (2007) but the difference is mostly due to recent changes in the reaction rate of HFC-227ea with $\mathrm{OH}$ as reported in Atkinson et al. (2008).

Using the model the temporal trend in the global emissions was adjusted to match the trend of HFC-227ea from the firn model (Fig. 2). This has been done for the best, maximum and minimum mixing ratios derived from the firn air. The error bars shown in Fig. 2 are the root mean squares of the uncertainties from these minimum and maximum scenarios plus uncertainties in the $\mathrm{OH}$ loss of $+59 \%$ and $-40 \%$. The latter were derived from an uncertainty of $14 \%$ in the $\mathrm{OH}$ concentrations (Prinn et al, 2001) and an uncertainty range of $-37 \%$ to $+57 \%$ in the reaction rate coefficient at $298 \mathrm{~K}$ (Atkinson et al., 2008). Given the relatively long lifetime 


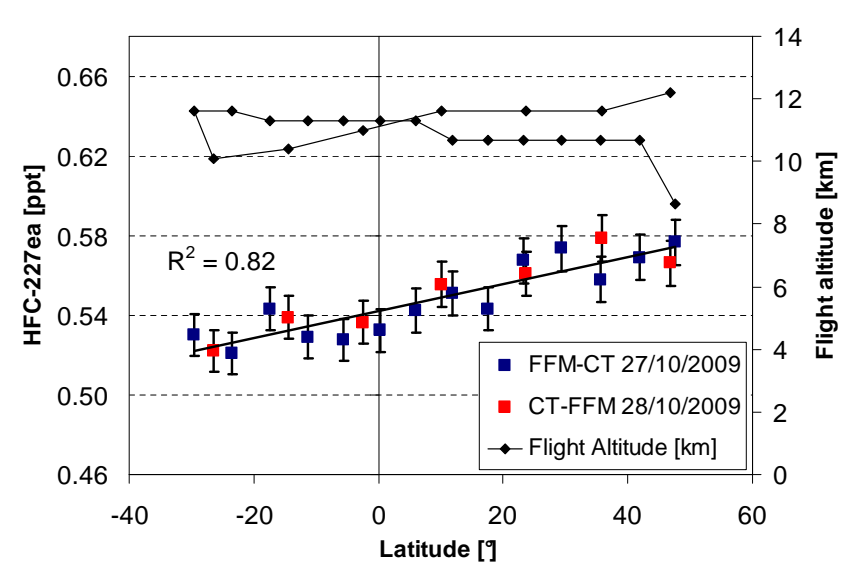

Fig. 3. Upper tropospheric mixing ratios of HFC-227ea as a function of latitude in air samples collected on board a Lufthansa aircraft during two flights from Frankfurt (Main), Germany (FFM) to Cape Town, South Africa (CT) and back. Two samples were collected at potential vorticity values indicating air from the tropopause region, but due to the long stratospheric lifetime of HFC-227ea this has little influence on the correlation.

of HFC-227ea compared to the period of rapidly increasing emissions, the uncertainty in this loss rate has a negligible impact on the derived emissions.

Also shown in Fig. 2 are the emissions from "bottom-up" estimates based on industrial production and use (EDGAR, 2009). The annual estimates for the years 1999 to 2001 from EDGAR are around twice those derived from the firn data and the respective discrepancy increases with time from 2001 on reaching a factor of 3.0 in 2005 . The firn and emission model uncertainties as well as the above mentioned uncertainties connected to $\mathrm{OH}$ cannot bridge this gap. We suspect that the discrepancy is likely to be caused by an overestimation of the bottom-up emissions. However, the currently available data are of insufficient temporal and spatial coverage to verify this suspicion.

\subsection{Upper tropospheric data and stratospheric lifetime}

Mixing ratios from upper tropospheric air samples collected in October 2009 (CARIBIC) are given in Fig. 3. The transect from $48^{\circ} \mathrm{N}$ (Frankfurt) to $30^{\circ} \mathrm{S}$ (Cape Town) was nearly true north-south (between 6 and $19^{\circ} \mathrm{E}$ ) and reveals a compact linear trend of HFC-227ea with latitude. This systematic behaviour with little scatter indicates that the observed air masses had not been in contact with sources recently and were representative for the upper troposphere at the given time and location. Backward trajectories (publicly available at http://www.knmi.nl/samenw/campaign_support/ CARIBIC) indicate that, with the exception of the ITCZ region, air masses had been predominantly advected over the Atlantic Ocean from the west. The observed north-south gradient implies that the source regions are in the Northern Hemisphere. To maintain such a gradient also implies that

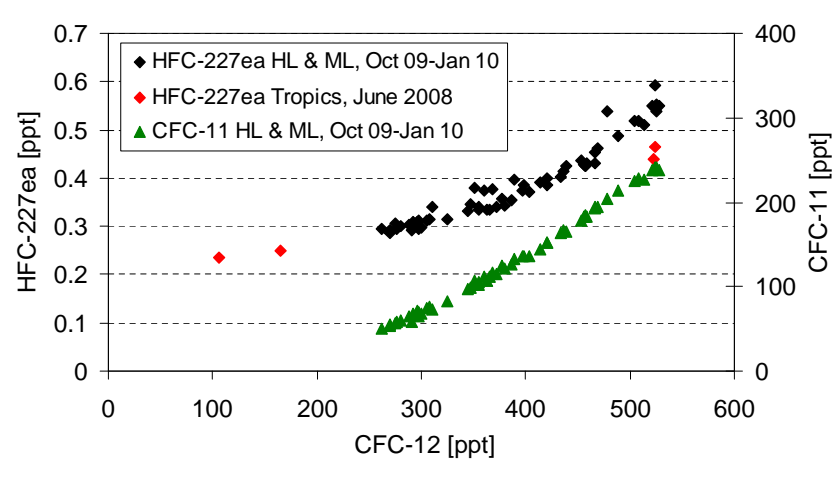

Fig. 4. Stratospheric correlation of HFC-227ea (black) and CFC-11 (green) with CFC-12 as derived from measurements on air samples collected on board the Geophysica high altitude aircraft in high and mid-latitudes (HL and ML). The red points belong to four samples collected with a balloon-borne whole-air sampler in the tropical upper troposphere and stratosphere (only CFC-12 vs. HFC-227ea displayed). The $1 \sigma$ measurement uncertainties are less than the size of the symbols in all cases.

HFC-227ea mixing ratios were still increasing in 2009. Assuming, that the observed mixing ratios are representative of the global upper troposphere, we calculate that the interhemispheric ratio $(\mathrm{NH} / \mathrm{SH})$ must be at least 1.1.

The stratospheric data are shown in Fig. 4 as a function of the concomitant $\mathrm{CF}_{2} \mathrm{Cl}_{2}$ (CFC-12) mixing ratios. Long-lived organic compounds are known to form such compact correlations in this atmospheric region (Plumb and Ko, 1992). As an example the correlation of CFC-12 with $\mathrm{CFCl}_{3}$ (CFC-11) is also displayed in Fig. 4. The slope of these correlations at the tropopause can be used to calculate a stratospheric lifetime (Volk et al., 1997). However, vertical stratospheric transport times are very slow (on the order of years). Thus, a correction must be made to account for the change in the entry mixing ratios over time. Here we use a method based on the mean age of air (i.e. the mean stratospheric transit time of a given air parcel) as derived from mixing ratios of $\mathrm{SF}_{6}$ and its global tropospheric trends from NOAA-ESRL which were obtained from http://www.esrl.noaa.gov/gmd/ (updated from Geller et al., 1997). Please refer to Engel et al. (2002) for further details on the mean age calculation. As global tropospheric trends are only available until early 2009 yet, we complemented it via an extension to the values observed at the tropopause in late 2009. Subsequently the above determined tropospheric trend of HFC-227ea was shifted by 6 months to account for transport into the tropics and then propagated into the stratosphere assuming no chemical degradation en route. The difference between this and the actual measured mixing ratios in the stratosphere is the inorganic fraction released at a given altitude. This inorganic fraction relative to the amount that initially entered the stratosphere is then the Fractional Release Factor (FRF). Thus, FRFs represent the detrended relative inorganic fraction released from a given long-lived compound at a given location and time in 
the stratosphere. The exact method for their calculation is described in Laube et al. (2010). If such a set of FRFs for two compounds are multiplied by their globally representative mixing ratios it yields their detrended correlation for a given date. After this correction it is possible to calculate the stratospheric lifetime $\tau_{\text {strat }}$ via the known lifetime of a reference compound $\tau_{\text {ref }}$ using Eq. (1) (adapted from Volk et al., 1997).

$$
\tau_{\text {strat }}=\tau_{\text {strat, ref }} \frac{\bar{\sigma}}{\bar{\sigma}_{\text {ref }}} /\left[\frac{d \chi}{d \chi_{\text {ref }}} \mid \chi_{\text {ref }}^{\text {trop }}\right]
$$

The reference compounds used here were CFC-11 and CFC-12 and their global average atmospheric mixing ratios $\bar{\sigma}$ (which take into account the loss in the stratosphere) were inferred by adjusting the values derived by Volk et al. (1997) to the mixing ratios observed at the tropopause in late 2009 (using monthly averaged NOAA-ESRL global tropospheric trends from Montzka et al., 1999 for detrending, as updated and publicly available from http://www.esrl.noaa.gov/ $\mathrm{gmd} /$ ).The slope of the detrended correlation already indicates that HFC-227ea is significantly longer-lived than CFC12. Therefore we performed calculations with values of $\bar{\sigma}$ between 95 and $100 \%$ of the mixing ratio observed at the tropopause (95\% is the value for CFC-12). The final unknown quantity $\left(d \chi / d \chi_{\text {ref }} \mid \chi_{\text {ref }}^{\text {trop }}\right)$ is the slope of the mixing ratio correlation at the tropopause. This was calculated from a least-square quadratic polynomial fit through the data.

Assuming a stratospheric lifetime of 45 years for CFC-11 (taken from Clerbaux and Cunnold, 2007) results in a stratospheric lifetime of 380 years for HFC-227ea for $\bar{\sigma}=100 \%$ (negligible stratospheric loss) and 360 years for $\bar{\sigma}=95 \%$ (same loss as CFC-12). As the exact value is likely to be between these values we infer 370 years as the best estimate. Calculations using the correlation with CFC-12 (100 year lifetime), different lifetimes of the CFCs (41 and 79 years, from Volk et al., 1997) as well as the above stated different values for $\bar{\sigma}$ give a range of 330 to 490 years. To assess the uncertainties of the correlation slope we performed similar calculations after subtraction and addition of the $1 \sigma$ measurement uncertainty from the ten data points next to the tropopause. This test revealed the limitations of this method for very long-lived compounds with correlation slopes close to zero. The corresponding lifetime range was 270 to 840 years. Due to the rather long tropospheric lifetime of HFC-227ea (37.8 years, Naik et al., 2000) uncertainties related to its tropospheric decomposition should have only a minor impact on this range. Thus, our experimentally derived stratospheric lifetime (best estimate of 370 years) agrees with the model-derived 633 years of Naik et al. (2000) within the respective uncertainties. However, it should be noted, that there are further uncertainties related to the approximated global tropospheric trend which can not be accounted for so far.

\section{Conclusions}

We report the first observations of HFC-227ea, a replacement for ozone depleting CFCs and halons, in remote regions of the atmosphere (i.e. in firn air and high-altitude samples). A dilution system has been built and evaluated for quantification of this and other compounds. A mass spectrum has been obtained and all high abundant ions of a spectrum reported in the literature were found to be present except one. A reconstruction of the atmospheric history of HFC-227ea from firn air reveals that emissions were very low in the early 1990s. In combination with further measurements in the upper troposphere we find strong evidence for its growth until the end of our available observations in 2009. Emission estimates inferred from this trend do not agree with estimates from the EDGAR database (EDGAR, 2009) and even show a discrepancy that is increasing with time. We can not resolve these disagreements with the observations and the related uncertainties presented here. Further studies, which should include observations from global ground-based networks, are needed to improve the understanding of the emission processes and patterns and the global distribution of HFC-227ea. Finally, compact correlations with other long-lived gases in the stratosphere have been used to derive a stratospheric lifetime of 370 years (range: 270 to 840 years) which agrees with the 633 years reported by Naik et al. (2000) within the uncertainties. It is the first time that this measurement-based approach has been used to evaluate a modelled stratospheric HFC lifetime.

Acknowledgements. We would like to thank the UK Natural Environment Research Council (Research Fellowship NE/F015585/1 \& Research Award NE/F021194/1), the European Union (SCOUT-O3 project GOCE-CT-2003-505390), the European Space Agency and CNRS-INSIS (PEPS-automatique project MODELINEVE) for funding. NEEM is directed and organized by the Center of Ice and Climate at the Niels Bohr Institute and US NSF, Office of Polar Programs. It is supported by funding agencies and institutions in Belgium (FNRS-CFB and FWO), Canada (GSC), China (CAS), Denmark (FIST), France (IPEV, CNRS/INSU, CEA and ANR), Germany (AWI), Iceland (RannIs), Japan (NIPR), Korea (KOPRI), The Netherlands (NWO/ALW), Sweden (VR), Switzerland (SNF), UK (NERC) and the USA (US NSF, Office of Polar Programs). The Geophysica flights from Oberpfaffenhofen were funded by ESA under the PremieEx project and by Forschungszentrum Jülich. The Geophysica flights from Kiruna were funded by the EC as part of the FP7 project RECONCILE (Grant number: RECONCILE-226365-FP7-ENV-2008-1). In addition we are grateful for contributions from Thijs F. Duindam, all CARIBIC partners, the Geophysica team and the CNES balloon team (sample collection and campaign organisation) as well as from the NOAA-ESRL GMD, AGAGE and WMO GAW teams and from CSIRO Marine and Atmospheric Research, Australia, the Institute of Arctic and Alpine Research (INSTAAR) at the University of Colorado at Boulder, USA and the IUP Heidelberg, Germany (provision of publicly available and also unpublished data).

Edited by: R. MacKenzie 


\section{Supplementary material related to this article is available online at: http://www.atmos-chem-phys.net/10/5903/2010/ acp-10-5903-2010-supplement.pdf.}

\section{References}

Atkinson, R., Baulch, D. L., Cox, R. A., Crowley, J. N., Hampson, R. F., Hynes, R. G., Jenkin, M. E., Rossi, M. J., Troe, J., and Wallington, T. J.: Evaluated kinetic and photochemical data for atmospheric chemistry: Volume IV - gas phase reactions of organic halogen species, Atmos. Chem. Phys., 8, 4141-4496, doi:10.5194/acp-8-4141-2008, 2008.

Bräunlich, M., Aballain, O., Marik, T., Jöckel, P., Brenninkmeijer, C. A. M., Chappellaz, J., Barnola, J.-M., Mulvaney, R., and Sturges, W. T.: Changes in the global atmospheric methane budget over the last decades inferred from ${ }^{13} \mathrm{C}$ and $\mathrm{D}$ isotopic analysis of Antarctic firn air, J. Geophys. Res., 106(D17), 2046520481, 2001.

Brenninkmeijer, C. A. M., Crutzen, P., Boumard, F., Dauer, T., Dix, B., Ebinghaus, R., Filippi, D., Fischer, H., Franke, H., Frieß, U., Heintzenberg, J., Helleis, F., Hermann, M., Kock, H. H., Koeppel, C., Lelieveld, J., Leuenberger, M., Martinsson, B. G., Miemczyk, S., Moret, H. P., Nguyen, H. N., Nyfeler, P., Oram, D., O’Sullivan, D., Penkett, S., Platt, U., Pupek, M., Ramonet, M., Randa, B., Reichelt, M., Rhee, T. S., Rohwer, J., Rosenfeld, K., Scharffe, D., Schlager, H., Schumann, U., Slemr, F., Sprung, D., Stock, P., Thaler, R., Valentino, F., van Velthoven, P., Waibel, A., Wandel, A., Waschitschek, K., Wiedensohler, A., Xueref-Remy, I., Zahn, A., Zech, U., and Ziereis, H.: Civil Aircraft for the regular investigation of the atmosphere based on an instrumented container: The new CARIBIC system, Atmos. Chem. Phys., 7, 4953-4976, doi:10.5194/acp-7-4953-2007, 2007.

Butler, J. H., Battle, M., Bender, M. L., Montzka, S. A., Clarke, A. D., Saltzman, E. S., Sucher, C. M., Severinghaus, J. P., and Elkins, J. W.: A record of atmospheric halocarbons during the twentieth century from polar firn air, Nature, 399, 749-755, 1999.

Chen, N. H. and Othmer, D. F.: New generalized equation for gas diffusion coefficient, J. Chem. Engin. Data, 7, 37-41, 1962.

Clerbaux, C. and Cunnold, D. M., Anderson, J., et al.: Halogenated Long-lived Compounds, Scientific assessment of ozone depletion: 2006, Global Ozone Research and Monitoring Project Report No. 50, Chapter 1, World Meteorological Organization, Geneva, 2007.

Deger, H.: FCKW: Anwendungen, Probleme und Wege zu deren Lösung, Nachr. Chem. Tech. Lab., 40, 1124-1132, 1992.

EDGAR, 2009: European Commission, Joint Research Centre (JRC)/Netherlands Environmental Assessment Agency (PBL). Emission Database for Global Atmospheric Research (EDGAR), release version 4.0. http://edgar.jrc.ec.europa.eu, 2009.

Emmen, H. H., Hoogendijk, E. M., Klopping-Ketelaars, W. A., et al.: Human safety and pharmacokinetics of the CFC alternative propellants HFC 134a (1,1,1,2-tetrafluoroethane) and HFC 227 (1,1,1,2,3,3,3-heptafluoropropane) following whole-body exposure. Regul Toxicol. Pharmacol., 32, 22-35, 2000.

Engel A., Strunk, M., Müller, M., Haase, H.-P., Poss, C., Levin, I., and Schmidt, U.: Temporal development of total chlorine in the high-latitude stratosphere based on reference distributions of mean age derived from $\mathrm{CO}_{2}$ and $\mathrm{SF}_{6}$, J. Geophys. Res., 107(D12), 4136, doi:10.1029/2001JD000584, 2002.

Fabre, A., Barnola, J.-M., Arnaud, L., and Chappellaz, J.: Determination of gas diffusivity in polar firn: comparison between experimental measurements and inverse modeling, Geophys. Res. Lett., 27, 557-560, 2000.

Forster, P., Ramaswamy, V., Artaxo, P., et al.: Changes in Atmospheric Constituents and in Radiative Forcing. In: Climate Change 2007: The Physical Science Basis. Contribution of Working Group I to the Fourth Assessment Report of the Intergovernmental Panel on Climate Change, Cambridge University Press, Cambridge, UK and New York, NY, USA, 2007.

Fraser, P. J., Oram, D. E., Reeves, C. E., Penkett, S. A., and McCulloch, A.: Southern Hemispheric halon trends (1978-1998) and global halon emissions, J. Geophys. Res., 104(D13), 1598515999, 1999.

Fuller, E. N., Schettler, P. D., and Giddings, J. C.: A new method for prediction of binary gas-phase diffusion coefficients, Ind. Eng. Chem., 58, 19-27, doi:10.1021//ie50677a007, 1966.

Geller, L. S., Elkins, J. W., Lobert, J. M., Clarke, A. D., Hurst, D. F. Butler, J. H., and Myers, R. C.: Tropospheric SF 6 : Observed latitudinal distribution and trends, derived emissions and interhemispheric exchange time, Geophys. Res. Lett., 24, 675-678, 1997.

Greally, B. R., Manning, A. J., Reimann, S., et al.: Observations of 1,1-difluoroethane (HFC-152a) at AGAGE and SOGE monitoring stations in 1994-2004 and derived global and regional emission estimates, J. Geophys. Res., 112, D06308, doi:10.1029/2006JD007527, 2007.

Hough, A. M.: The development of a two-dimensional global tropospheric model, 1, The model transport, Atmos. Environ., 23, 1235-1261, 1989.

Hynes, R. G., Mackie J. C., and Masri. A. R.: Inhibition of Premixed Hydrogen-Air Flames by 2-H Heptafluoropropane, Combust. Flame, 113, 554-565, 1998.

Jager, D. de, Manning, M., Kuijpers, L., et al.: IPCC/TEAP Special Report on Safeguarding the Ozone Layer and the Global Climate System: Issues related to Hydrofluorocarbons and Perfluorocarbons, Cambridge University Press, Cambridge, 2005.

Kaiser, J., Engel, A., Borchers, R., and Röckmann, T.: Probing stratospheric transport and chemistry with new balloon and aircraft observations of the meridional and vertical $\mathrm{N}_{2} \mathrm{O}$ isotope distribution, Atmos. Chem. Phys., 6, 3535-3556, doi:10.5194/acp6-3535-2006, 2006.

Karecki, S., Pruette, L., Reif, R., Sparks, T., Beu, L., and Vartanian, V.: Use of novel hydrofluorocarbon and iodofluorocarbon chemistries for a high aspect ratio via etch in a high density plasma etch tool, J. Electrochem. Soc., 145 (12), 4305-4312, 1998.

Laube, J. C., Engel, A., Bönisch, H., Möbius, T., Worton, D. R., Sturges, W. T., Grunow, K., and Schmidt, U.: Contribution of very short-lived organic substances to stratospheric chlorine and bromine in the tropics - a case study, Atmos. Chem. Phys., 8, 7325-7334, doi:10.5194/acp-8-7325-2008, 2008.

Laube, J. C., Engel, A., Bönisch, H., Möbius, T., Sturges, W. T., Braß, M., and Röckmann, T.: Fractional release factors of long-lived halogenated organic compounds in the tropical stratosphere, Atmos. Chem. Phys., 10, 1093-1103, doi:10.5194/acp- 
10-1093-2010, 2010.

MacFarling Meure, C., Etheridge, D., Trudinger, C., Steele, P., Langenfelds, R., van Ommen, T., Smith, A., and Elkins, J.: Law Dome $\mathrm{CO}_{2}, \mathrm{CH}_{4}$ and $\mathrm{N}_{2} \mathrm{O}$ ice core records extended to 2000 years BP, Geophys. Res. Lett., 33, L14810, doi:10.1029/2006GL026152, 2006.

Martinerie, P., Nourtier-Mazauric, E., Barnola, J.-M., Sturges, W. T., Worton, D. R., Atlas, E., Gohar, L. K., Shine, K. P., and Brasseur, G. P.: Long-lived halocarbon trends and budgets from atmospheric chemistry modelling constrained with measurements in polar firn, Atmos. Chem. Phys., 9, 3911-3934, doi:10.5194/acp-9-3911-2009, 2009.

Massman, W. J.: A review of the molecular diffusivities of $\mathrm{H}_{2} \mathrm{O}$, $\mathrm{CO}_{2}, \mathrm{CH}_{4}, \mathrm{CO}, \mathrm{O}_{3}, \mathrm{SO}_{2}, \mathrm{NH}_{3}, \mathrm{~N}_{2} \mathrm{O}, \mathrm{NO}$, and $\mathrm{NO}_{2}$ in air, $\mathrm{O}_{2}$ and $\mathrm{N}_{2}$ near STP, Atmos. Environ., 32, 1111-1127, 1998.

Montzka, S. A., Myers, R. C., Butler, J. H., Elkins, J. W., Lock, L. T., Clarke, A. D., Goldstein, A. H.: Observations of HFC-134a in the remote troposphere, Geophys. Res. Lett., 23(2), 169-172, 1996.

Montzka, S. A., Butler, J. H., Elkins, J. W., Thompson, T. M., Clarke, A. D., and Lock, L. T.: Present and future trends in the atmospheric burden of ozone-depleting halogens, Nature, 398, 690-694, 1999.

Naik, V., Jain, A. K., Patten, K. O., and Wuebbles, D. J.: Consistent sets of atmospheric lifetimes and radiative forcings on climate for CFC replacements: HCFCs and HFCs, J. Geophys. Res., 105, 6903-6914, 2000.

O'Doherty, S., Cunnold, D. M., Miller, B. R., et al.: Global and regional emissions of HFC-125 (CHF2CF3) from in situ and air archive atmospheric observations at AGAGE and SOGE observatories, J. Geophys. Res., 114, D23304, doi:10.1029/2009JD012184, 2009.

Oram, D. E., Sturges, W. T., Penkett, S. A., McCulloch, A., and Fraser, P. J.: Growth of fluoroform $\left(\mathrm{CHF}_{3}, \mathrm{HFC}-23\right)$ in the background atmosphere, Geophys. Res. Lett., 25, 35-38, 1998.

Park, J.-Y., Lim, J. S., Lee B. G., and Lee, Y. W.: Phase equilibria of CFC alternative refrigerant mixtures: 1,1,1,2,3,3,3heptafluoropropane (HFC-227ea)+difluoromethane (HFC-32), $+1,1,1,2$-tetrafluoroethane (HFC-134a), and +1,1-difluoroethane (HFC-152a), Int. J. Thermophys., 22, 901-917, 2001.

Prinn, R. G., Weiss, R. F., Fraser, P. J., Simmonds, P. G., Cunnold, D. M., Alyea, F. N., O’Doherty, S., Salameh, P., Miller, B. R., Huang, J., Wang, R. H. J., Hartley, D. E., Harth, C., Steele, L. P., Sturrock, G., Midgley, P. M., and McCulloch, A.: A History of Chemically and Radiatively Important Gases in Air deduced from ALE/GAGE/AGAGE, J. Geophys. Res., 105, 17751-17792, 2000.
Prinn, R. G., Huang, J., Weiss, R. F., Cunnold, D. M., Fraser, P. J., Simmonds, P. G., McCulloch, A., Harth, C., Salameh, P., O’Doherty, S., Wang, R. H. J., Porter, L., and Miller, B. R.: Evidence for substantial variations of atmospheric hydroxyl radicals in the past two decades, Science, 292(5523), 1882-1888, 2001.

Plumb, R. A. and Ko, M. K. W.: Interrelationships between mixing ratios of long-lived stratospheric constituents, J. Geophys. Res., 97, 10145-10156, 1992.

Reeves, C. E., Sturges, W. T., Sturrock, G. A., Preston, K., Oram, D. E., Schwander, J., Mulvaney, R., Barnola, J.-M., and Chappellaz, J.: Trends of halon gases in polar firn air: implications for their emission distributions, Atmos. Chem. Phys., 5, 2055-2064, doi:10.5194/acp-5-2055-2005, 2005.

Rommelaere V., Arnaud, L., and Bamola, J. M.: Reconstructing recent atmospheric, trace gas concentrations from polar firn and bubbly ice data by inverse methods, J. Geophys. Res., 102(D25), 30069-30083, 1997.

Schwander, J., Barnola, J.-M., Andrie, C., Leuenberger, M., Ludin, A., Raynaud, D., and Stauffer, B.: The age of the air in the firn and ice at Summit, Greenland, J. Geophys. Res., 98, 2831-2838, 1993.

Stemmler, K., Folini, D., Ubl, S., Vollmer, M. K., Reimann, S., O'Doherty, S., Greally., B. R., Simmonds, P. G., and Manning., A. J.: European emissions of HFC-365mfc, a chlorine free substitute for the foam blowing agents HCFC-141b and CFC-11, Environ. Sci. Technol., 41, 1145-1151, 2007.

Sturrock, G. A., Etheridge, D. M., Trudinger, C. M., Fraser, P. J., and Smith, A. M.: Atmospheric histories of halocarbons from analysis of Antarctic firn air: Major Montreal Protocol species, J. Geophys. Res., 107, 4765, doi:10.1029/2002JD002548, 2002.

Volk, C. M., Elkins, J. W., Fahey, D. W., Sutton, G. S., Gilligan, J. M., Loewenstein, M., Podolske, J. R., Chan, K. R., and Gunson, M. R.: Evaluation of source gas lifetimes from stratospheric observations, J. Geophys. Res., 102(D21), 25543-25564, 1997.

Vollmer, M. K., Reimann, S., Folini, D., Porter, L. W., and Steele, L. P.: First appearance and rapid growth of anthropogenic HFC$245 \mathrm{fa}(\mathrm{CHF} 2 \mathrm{CH} 2 \mathrm{CF} 3)$ in the atmosphere, Geophys. Res. Lett., 33, L20806, doi:10.1029/2006GL026763, 2006.

Yquel, J.-P.: Aerosol device for dispensing a composition with relatively high viscosity, US Patent 5467902, 1995.

Zellner, R., Bednarek, G., Hoffmann, A., Kohlmann, J. P., Mörs, V., and Saathoff, H.: Rate and Mechanism of the Atmospheric Degradation of 2H-Heptafluoropropane (HFC-227), Ber. Bunsenges. Phys. Chem., 98, 141-146, 1994. 